\title{
A promoção do cuidado materno ao neonato prematuro: a perspectiva da educação problematizadora em saúde
}

\section{Promoting mothers' care for premature neonates: the perspective of problem-based education in health \\ La promoción del cuidado materno al neonato prematuro: la perspectiva de la educación problematizadora en salud}

\author{
Bárbara Bertolossi Marta de AraújoI; Benedita Maria Rêgo Deusdará Rodrigues ${ }^{I I}$; Sandra Teixeira de Araújo Pacheco ${ }^{I I I}$
}

\begin{abstract}
RESUMO: O objetivo deste estudo é refletir sobre a educação em saúde inspirada na educação problematizadora de Freire, visando a promoção do cuidado materno emancipatório ao recém-nascido prematuro pela equipe de enfermagem. Inicialmente, enfoca-se o cuidado materno na unidade neonatal, seguido da educação problematizadora em saúde e da promoção do cuidado materno pela enfermagem na unidade neonatal, tendo como base os princípios da dialogicidade e respeito pelo outro. A educação em saúde inspirada na educação problematizadora de Freire deve fazer parte da práxis da equipe de enfermagem e, em especial, do enfermeiro. Assim, a mãe do prematuro pode habilitar-se a participar dos cuidados de seu filho, bem como das decisões sobre as condutas terapêuticas a ele direcionadas, redefinindo seu espaço na unidade neonatal. Palavras-Chave: Mães; prematuro; educação em saúde; enfermagem.
\end{abstract}

ABSTRACT: This study discusses health education inspired in the problem-based education of Freire, with a view to nursing staffs' promoting emancipatory care by mothers for their premature babies. It focuses first on care by mothers in a neonatal unit, followed by problem-based education in health, and nurses' promotion of maternal care in the neonatal unit, all based on the principles of dialog and respect for others. Health education inspired in Freire's problem-based education should form part of the praxis of nursing teams, and especially of nurses. In this way, the premature baby's mother may be enabled to participate in care for her child, and in decisions on therapeutic conduct towards the child, thus redefining her place in the neonatal unit. Keywords: Mothers; premature; health education; neonatal nursing.

RESUMEN: El objetivo de este trabajo es discutir la educación en salud inspirada en la educación problematizadora de Freire, destinada a promover el cuidado materno emancipatorio para bebé prematuro por el personal de enfermería. Inicialmente, se centra en el cuidado materno en la unidad neonatal, seguido por la educación problematizadora en salud y de la promoción del cuidado materno por las enfermeras en la unidad neonatal, basado en los principios del diálogo y del respeto por los demás. Educación en salud inspirada en la educación problematizadora de Freire debe ser parte de la práctica del equipo de enfermería y, sobre todo, del enfermero. Así, la madre del prematuro puede calificarse para participar del cuidado de su niño y de las decisiones sobre enfoques terapéuticos para él, con redefinición de su lugar en la unidad neonatal.

Palabras Clave: Madres; prematuro; educación en salud; enfermería.

\section{INTRODUÇÃO}

A mortalidade infantil declinou de forma expressiva nos últimos 30 anos em todo mundo. No Brasil, apesar da sua redução substancial de aproximadamente $75 \%$ ser bem maior do que a média mundial de $40 \%$, ela ainda permanece acima dos valores referentes aos países desenvolvidos ${ }^{1-3}$.

Entretanto, mesmo com os avanços na área de neonatologia, desde o fim da década de 80 , a mortalidade neonatal representa o principal componente da mortali- dade infantil no Brasil. A melhoria da assistência e do acesso à saúde, assim como o aumento da viabilidade fetal, desloca esses óbitos para o período neonatal precoce e aponta novas necessidades de atenção à saúde ${ }^{4}$.

Nesse sentido, as Políticas Públicas implantadas, bem como os investimentos em tecnologia de ponta e cuidados especializados, vêm garantindo a sobrevivência dos neonatos com peso e idade gestacional cada vez menores. No entanto, os distúrbios funcio-

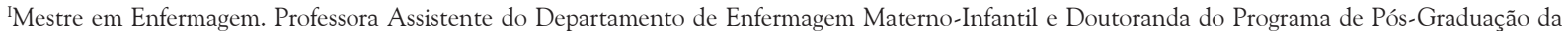
Faculdade de Enfermagem da Universidade do Estado do Rio de Janeiro. Brasil. E-mail: betaberolossi@gmail.com

IIProfessora Titular do Departamento de Enfermagem Materno-Infantil da Faculdade de Enfermagem da Universidade do Estado do Rio de Janeiro. Brasil. E-mail: benedeusdara@gmail.com

IIIProfessora Adjunta do Departamento de Enfermagem Materno-Infantil da Faculdade de Enfermagem da Universidade do Estado do Rio de Janeiro. Brasil. E-mail: stapacheco@yahoo.com.br

${ }^{\mathrm{IV}}$ Recorte da tese de doutorado intitulada O cuidado materno em neonatologia: o discurso da educação em saúde na perspectiva do profissional de enfermagem,

Programa de Pós-Graduação da Faculdade de Enfermagem da Universidade do Estado do Rio de Janeiro, 2015. 
nais, as alterações neurológicas motoras, cognitivas e sensoriais, juntamente com atraso no crescimento e desenvolvimento e as repercussões sociais e familiares, passaram a ser um problema de saúde pública ${ }^{5}$.

A incorporação desse ser prematuro na sociedade passa por uma série de fatores intimamente relacionados com a saúde mental, social e familiar. Nessa perspectiva, a família, principalmente a mãe, deve ser considerada uma aliada no processo de crescimento e desenvolvimento do bebê prematuro desde o nascimento ${ }^{5}$.

Diante do bebê prematuro, é essencial que a mãe tenha suporte para conhecer o filho, de modo que identifique suas habilidades, competências e respostas na interação com o meio. Esse suporte pode ser oferecido através da promoção do cuidado materno ${ }^{6}$.

O cuidado materno representa um conjunto de ações ambientais e biopsicossociais que possibilita a atenção integral à mãe com o seu filho, de forma que este se desenvolva bem ao seu lado. Entre os benefícios da participação materna nos cuidados ao filho prematuro, destacam-se significativo ganho ponderal do bebê, a promoção de condutas neuro-comportamentais e cognitivas da criança e da modelagem da arquitetura cerebral, melhora no tratamento clínico, tais como a redução do grau de dependência da ventilação artificial, desenvolvimento de sucção não nutritiva mais precoce e autorregulação. Enfim, o cuidado materno ainda é responsável por diminuir o tempo de internação, os custos do cuidado prestado, a procura em unidades de pronto-atendimento 24 horas após a alta hospitalar, bem como o número de reinternações nos hospitais ${ }^{7,8}$.

Diante do exposto, o presente estudo ${ }^{\mathrm{IV}}$ objetivou refletir sobre a importância da educação em saúde inspirada na educação problematizadora de Freire ${ }^{9}$, visando a promoção do cuidado materno emancipatório ao bebê prematuro pela equipe de enfermagem. Dessa forma, inicialmente enfoca-se a importância do cuidado materno ao prematuro na unidade neonatal, seguida da educação problematizadora em saúde e seus princípios e da promoção do cuidado materno pela enfermagem neonatal.

Nesse pensar, a realização deste estudo se justifica pela relevância do cuidado materno no empoderamento da mulher-mãe e pelos benefícios advindos dessa transformação junto ao filho prematuro.

\section{O Cuidado Materno na Unidade NEONATAL}

O compromisso do cuidado materno ao recémnascido está diretamente relacionado aos laços afetivos estabelecidos entre mãe e filho. Da mesma forma, quando a mãe vê, toca e cuida do filho promove o estreitamento desses laços afetivos. Esse fenômeno de preocupação e afeição faz a mãe tornar-se comprometida com o filho que estiver sob seus cuidados durante os primeiros meses ou anos de vida ${ }^{10}$. $O$ poder dessa afetividade permite à mãe desenvolver sacrifícios, necessários ao cuidado do bebê, conferindo proteção, preocupação, provisão das necessidades do filho em detrimento de suas próprias necessidades, dia após dia, noite após noite ${ }^{11}$.

O cuidado materno é de fundamental importância para o crescimento e desenvolvimento do recém-nascido prematuro e a equipe de enfermagem é responsável por propiciar subsídios junto às mães para torná-lo adequado, eficaz, emancipatório e responsável.

A simples permanência dos pais na unidade neonatal, bem como o estímulo ao toque e conversas com o filho prematuro favorecem o vínculo afetivo profundo e duradouro. Esta vinculação desenvolve efeitos positivos no crescimento e desenvolvimento da criança. Dessa forma, o aconchego dos bebês pelos pais, mesmo quando se encontram em incubadoras ou suportes tecnológicos, deve ser estimulado. Esse contato promove aumento da temperatura corporal do bebê, o que favorece o ganho ponderal e a recuperação da saúde do prematuro ${ }^{4}$.

O toque é considerado ferramenta essencial para estimular o desenvolvimento do vínculo. Assim, quando a mãe toca e cuida do filho, os laços afetivos entre eles começam a se estreitar. $\mathrm{O}$ toque ainda tem fundamental importância na redução da sensação materna de incompetência e medo em manusear seu próprio filho, devido a sua aparência frágil e pequenina. $\mathrm{O}$ estímulo do toque a faz se sentir incluída no processo de cuidado ao filho, pois passa a ter mais segurança em realizar cuidados mais simples e, posteriormente, a confiança de suas habilidades no cuidado pós alta ${ }^{12,13}$.

\section{A Educação Problematizadora em SAÚdE}

A educação em saúde como processo políticopedagógico exige um pensar crítico e reflexivo, que permita tornar visível a realidade, propondo ações transformadoras que propiciem a autonomia e a emancipação do indivíduo como sujeito histórico e social com capacidade de propor e opinar nas decisões de saúde para o cuidado de si mesmo, de sua família e da coletividade ${ }^{14}$.

Desse modo, o conceito de educação em saúde ancora-se no conceito de promoção da saúde, que trata de processos direcionados à participação da população no cotidiano de sua vida e não apenas das pessoas doentes ou com risco de adoecer. Essa concepção se apoia no conceito de saúde como um estado positivo e dinâmico de busca de bem-estar, integrando os aspectos físicos e mentais, ambiental, pessoal e social ${ }^{14}$.

A educação em saúde inspirada nos pensamentos de Freire, competente e coerente, testemunha sua esperança num mundo melhor, atestando sua capacidade de luta, seu respeito a realidades diferentes e a forma 
consistente com que vive sua presença no mundo. Dessa forma, para educar em saúde, é preciso estar aberto ao contorno geográfico, social, político, cultural do indivíduo, família e comunidade ${ }^{15}$.

A educação problematizadora idealizada por Freire fundamenta-se na criatividade, estimulando uma ação e uma reflexão sobre a realidade de forma a responder a real vocação dos homens. Assim sendo, esta educação está alicerçada na concepção de homem como um ser histórico e autêntico, senão quando comprometido na procura e na transformação criadoras ${ }^{16}$.

Considerando que os homens são históricos, inacabados e inconclusos, entende-se que são capazes de escolher, de decidir, de transformar e de lutar, com ética, de forma política, configurando, assim, as bases antropológico-filosóficas de uma educação problematizadora com propósitos emancipatórios ${ }^{9}$.

A Educação Problematizadora de Freire sustenta como um de seus princípios o ato de ensinar sem transferir conhecimentos ou conteúdos, instigando a criação de condições para a sua produção ou sua construção através de um processo educativo baseado na dialogicidade. Nessa forma de educar, Freire preconiza o respeito ao diálogo e a união entre ação e reflexão. Ainda, defende que não há educador sem educando, e sendo reservadas as diferenças de cada uma das partes, ambos são sujeitos, não devendo ser reduzidos a condição de objeto um do outro. Nesse sentido, o ensinamento e o aprendizado são recíprocos ${ }^{17}$.

\section{A dialogicidade na educação em saúde}

O diálogo é um fenômeno humano que nos revela algo que representa ele mesmo, que é a palavra e seus elementos constitutivos. Na palavra, são observadas duas dimensões, a ação e a reflexão, expressando a práxis e possibilitando a transformação do mundo ${ }^{17}$.

Na palavra inautêntica, não se pode transformar a realidade, sendo esta esgotada de sua dimensão de ação, sacrificando a reflexão e se transformando em palavreado, verbalismo e palavra oca. Em contrapartida, quando se sacrifica a reflexão e se enfatiza a ação, a palavra se transforma em ativismo, negando a práxis da ação e impossibilitando o diálogo. Nesse pensar, a palavra autêntica, que significa o trabalho, a práxis, a transformação do mundo, é privilégio de todos os homens. Esta não deve ser dita por ninguém estando sozinho, nem mesmo ser prescrita para outros seres humanos ${ }^{9}$.

O diálogo é o encontro dos homens, mediatizados pelo mundo, de forma a pronunciá-lo, sem deixar se esgotar a relação eu-tu. Assim, o diálogo se impõe existencialmente como caminho, ao qual os homens recebem suas significações como seres humanos ${ }^{17}$.

Assim, o diálogo não pode ser um ato de depositar ideias de um sujeito em outro ou mesmo a troca de ideias a serem consumidas entre si, nem tampouco representa uma discussão polêmica entre sujeitos que buscam impor a sua verdade. O diálogo é o encontro solidário entre o refletir e o agir dos seus sujeitos, endereçados ao mundo a ser modificado e humanizado. A dialogicidade se inicia desde o momento em que os educadores-educandos se perguntam sobre o que dialogarão com os educandoeducadores, sendo esta inquietação sobre o conteúdo do diálogo chamada de conteúdo programático? .

Portanto, a relação dialógica pressupõe então uma relação de direito e cidadania, na qual o profissional trabalha em horizontalidade com o usuário e não para ele.

Nessa perspectiva, promover o cuidado materno na unidade neonatal, através do diálogo, é um ato que deve fazer parte da práxis da equipe de enfermagem e, em especial, do enfermeiro. Pois, através da teoria da dialogicidade de Freire ${ }^{9,15-17}$, as pessoas podem despertar para a consciência crítica do mundo em que se encontram, saindo de sua condição de oprimidas para a condição do ser mais, em meio a um processo de humanização, em atendimento a uma vocação humana.

\section{A Promoção do Cuidado Materno PELA ENFERMAGEM}

Durante a hospitalização do neonato prematuro na unidade neonatal, a equipe de enfermagem deve estabelecer uma comunicação efetiva com as mães no intuito de instrumentalizá-las e empoderá-las a participar da assistência ao filho de forma autônoma. A participação das mães contribui para minimizar os efeitos da privação e do isolamento dos bebês, ainda podendo reduzir traumas decorrentes do processo terapêutico ${ }^{18}$.

Além disso, a segurança e a tranquilidade maternas, durante o período de internação do filho na unidade neonatal, podem ser alcançadas quando se instrumentaliza a mãe para cuidar do bebê, orientando e sanando dúvidas quanto ao estado de saúde e aos cuidados. As mães que participam dos cuidados ao filho prematuro e que participam da tomada de decisão empoyment durante a internação na unidade neonatal possuem ainda mais habilidades e menos ansiedade ao assumir responsabilidades no cuidado ao filho após a alta hospitalar ${ }^{6,19}$.

Neste pensar, a equipe de enfermagem deve incentivar as mães a verem e sentirem seus filhos, bem como orientá-las desde a admissão do bebê na unidade neonatal, devendo valorizar aspectos referentes às características do bebê, orientações sobre aleitamento materno, higiene, cuidados com o coto umbilical, vacinas, prevenção de infecções respiratórias e gastrointestinais, ensinar procedimentos quanto às intercorrências comuns nos prematuros (regurgitações e cólicas), banho, troca de fraldas, curativos, medicações, sono e repouso, prevenção de perda de calor e superaquecimento do bebê ${ }^{6}$.

Faz-se necessário, entretanto, que as orientações sobre cuidado materno ao filho sejam diárias e contínuas, devendo a mãe ser introduzida gradativamente no processo de cuidado. Inicialmente, estimula-se a 
realização de cuidados mais simples, como higiene, banho, troca de fraldas, toque, alimentação da criança e vai gradativamente aprofundando os cuidado até a assistência integral ${ }^{18}$.

Ao apropriar-se dos códigos de comunicação da equipe de enfermagem, a mãe do prematuro habilitase, da sua forma, para poder participar das decisões sobre as condutas terapêuticas direcionadas a seu filho. Este empoderamento nem sempre é bem aceito pelos membros da equipe de enfermagem, visto que estão habituados a decidirem entre eles os tratamentos a serem prestados a cada paciente. Assim, ao mesmo tempo em que o empoderamento materno causa certa estranheza e desconforto na equipe de enfermagem, a mãe redefine seu espaço na unidade neonatal. Uma vez que troca a imagem de fragilidade para uma posição mais assertiva em relação ao filho, a mãe passa a assumir seu lugar, capacitando-se a maternar seu filho, estimulando assim a interação ${ }^{20}$.

O empoderamento da mulher permite a mesma exigir seus direitos de cidadã e possibilita sua habilitação para um cuidado adequado ao filho prematuro, inclusive tomar decisões junto com os profissionais que atendem seus filhos, estando efetivamente incluída no processo de cuidar. Estar empoderado significa estar informado suficientemente para ter liberdade para decidir ${ }^{21}$.

\section{Considerações Finais}

A educação em saúde inspirada na educação problematizadora de Freire, visando a promoção do cuidado materno emancipatório ao bebê prematuro pela equipe de enfermagem, deve fazer parte da práxis da equipe de enfermagem e em especial, do enfermeiro. Pois, através da teoria da dialogicidade freireana, as pessoas podem despertar para a consciência crítica do mundo em que se encontram, saindo de sua condição de oprimidas, para a condição do ser mais, em meio a um processo de humanização, em atendimento a uma vocação humana.

Assim, a mãe do prematuro pode habilitar-se e participar dos cuidados de seu filho, bem como das decisões sobre as condutas terapêuticas a ele direcionadas, redefinindo seu espaço na unidade neonatal. Uma vez que troca a imagem de fragilidade para uma posição mais assertiva em relação ao filho, a mãe passa a assumir seu lugar, capacitando-se a maternar seu filho, exigir seus direitos de cidadã e possibilitar um cuidado adequado ao filho, estando assim incluída efetivamente no processo de cuidado.

\section{REFERÊNCIAS}

1.Siqueira MBC, Dias MAB. A percepção materna sobre vivência e aprendizado de cuidado de um bebê prematuro. Epidemiol serv saude. 2011; 20(1):27-36.

2.United Nations Children's Fund (Unicef). Committing to child survival: a promise renewed - progress reported. New York: UNICEF; 2012.

3.Ministério do Planejamento, Orçamento e Gestão (Br). Instituto Brasileiro de Geografia e Estatística. Tábuas abreviadas de mortalidade por sexo e idade. Brasil, grandes regiões e unidades da federação - 2010. Brasília (DF): IBGE; 2013. 4.Ministério da Saúde (Br). Secretaria de Atenção à Saúde. Atenção humanizada ao recém-nascido de baixo peso: método canguru. 2a ed. Brasília (DF): Editora MS; 2011. 5.Araújo BBM. Vivenciando a internação do filho prematuro na utin: (re)conhecendo as perspectivas maternas diante das demandas neonatais [dissertação de mestrado]. Rio de Janeiro: Universidade do Estado do Rio de Janeiro; 2007. 6.Sá FE, Sá RC, Pinheiro LMF, Callou FEO. Relações interpessoais entre os profissionais e as mães de prematuros da unidade canguru. RBPS. 2010; 23:144-9.

7.Martínez JG, Fonseca LMM, Scochi CGS. Participação das mães/pais no cuidado ao filho prematuro em unidade neonatal: significados atribuídos pela equipe de saúde. Rev Latino-Am Enfermagem. 2007;15: 239-46.

8.Silva ND, Vieira MRR. A atuação da equipe de enfermagem na assistência ao recém-nascido de risco em um hospital de ensino. Arq ciênc saúde. 2008; 15(3):110-6. 9.Freire P. Pedagogia do oprimido. $54^{\mathrm{a}} \mathrm{ed}$. Rio de Janeiro: Paz e Terra; 2013.

10.Klaus MH, Kennell JH. Pais /bebê: a formação do apego. Porto Alegre (RS): Artes Médicas; 1993.

11.Brazelton TB. O desenvolvimento do apego: uma família em formação. Porto Alegre (RS): Artes Médicas; 1998.

12.Costa R, Klock P, Locks MOH. Acolhimento na uti neonatal: percepção da equipe de enfermagem. Rev enferm UERJ. 2012; 20:357-8.

13.Gorgulho FR, Rodrigues BMD. A relação entre enfermeiros, mães e recém-nascidos em unidades de tratamento intensivo neonatal. Rev enferm UERJ. 2010; 18:541-6.

14.Machado MFAS, Monteiro EMLM, Queiroz DT, Vieira NFC, Barroso MGT. Integralidade, formação de saúde, educação em saúde e as propostas do sus - uma revisão conceitual. Ciência \& saúde coletiva. 2007; 12:335-42.

15.Freire P. Pedagogia da autonomia: saberes necessários à prática educativa. 45ª ed. Rio de Janeiro: Paz e Terra; 2013. 16.Freire P. Conscientização: teoria e prática da libertação. 3a ed. São Paulo: Centauro; 2013.

17.Freire P. Educação e mudança. $2^{\mathrm{a} e d . ~ S a ̃ o ~ P a u l o: ~ P a z ~}$ e Terra; 2011.

18.Silva RB, Oliveira BRG, Collet N, Viera CS. O papel da equipe de enfermagem nas orientações à família sobre os cuidados no domicílio ao rn egresso de uti neonatal: pesquisa bibliográfica. Online Brazilian J Nursing. 2006;5(3). 19.Chiodi LC, Aredes NDA, Scochi CGS, Fonseca LMM. Educação em saúde e a família do bebê prematuro: uma revisão integrativa. Acta Paul Enferm. 2012; 25:969-74. 20.Morsh DS, Braga MCA. À procura de um encontro perdido: o papel da preocupação médico-primária em uti neonatal. Rev Latinoam Psicopat Fund. 2007;10:624-36. 21.Neves ET, Cabral IE. A fragilidade clínica e a vulnerabilidade social das crianças com necessidades especiais de saúde. Rev Gaúcha Enferm.2008; 29:182-90. 